\title{
Cemented allograft-prosthesis composite reconstruction for the proximal femur tumor
}

This article was published in the following Dove Press journal:

OncoTargets and Therapy

25 August 2015

Number of times this article has been viewed

\author{
Li Min \\ Fan Tang \\ Hong Duan \\ Yong Zhou \\ Wen-li Zhang \\ Rui Shi \\ Chong-qi Tu \\ Department of Orthopedics, West \\ China Hospital, Sichuan University, \\ Chengdu, Sichuan, People's Republic \\ of China
}

Correspondence: Chong-qi Tu

Department of Orthopedics, West China Hospital, Sichuan University, \#37 Guoxue

Road, Chengdu, Sichuan, People's

Republic of China

Email tcqbonetumor@163.com
Introduction: Cemented allograft-prosthesis composite (APC) reconstruction is one option following resection of the proximal femur tumor. However, rare studies have focused on the indications and complications. The goal of the present study was to (1) ascertain the indications for cemented APC arthroplasty in the proximal femur; (2) identify the detailed perioperative management; and (3) illustrate our experiences to avoid the complications of cemented APC.

Materials and methods: A total 28 patients who underwent cemented APC reconstruction of the proximal femur after tumor resection were retrospectively evaluated at a median follow-up of 56 months. Clinical records and radiographs were reviewed to evaluate patients' outcome.

Results: In our series, excluding three cases of death that had a short follow-up period, union occurred in $22(88.0 \%$ ) patients (range 9-18 months). Nonunion of the greater trochanter was seen in six of the 12 patients $(50.0 \%)$. Eight $(32.0 \%)$ hips had resorption. There were two $(8.0 \%)$ hips that were observed to have asymptomatic wear of the acetabulum. The average Musculoskeletal Tumor Society (MSTS) score was 26.5 points. The average Harris Hip Score (HHS) score was 80.6 points. There were no cases of recurrence, but metastasis was found in two hips.

Conclusions: Mastering indications, perioperative management, and complication prevention are all very important in the APC reconstruction after resection of the proximal femur.

Keywords: bone tumor, surgical treatment, limb salvage

\section{Introduction}

Surgical treatment for primary malignant tumors and aggressive benign tumors in the proximal femur may involve wide excision of the proximal femur. Reconstruction of these surgically created defects is challenging because improved survival of patients with musculoskeletal tumors means that greater demands are placed on the reconstruction of the salvaged limb over longer time periods. Nowadays two of the most commonly used methods of reconstructing proximal femoral defects are the allograft-prosthesis composite (APC) and proximal femoral replacement prosthesis (megaprosthesis). ${ }^{1-4}$

The main advantage of APC compared with megaprosthesis is the effective reattachment of the tendons of the hip abductors and iliopsoas muscles, thereby preventing dislocation and allowing better function. In addition, the benefits of using APC include restoration of bone stock, provision of a biologic anchor for the attachment of tendon, biologic fixation, ease of revision, load sharing after union, and the ability to precisely adjust graft length. ${ }^{5}$ The limitations of the use of APC include infection, fracture, nonunion, resorption, disease transmission, and technique difficulties.

Most of the previous studies have reported on functional and radiographic outcomes, surgical procedure, and complications. But rare studies have focused on the indications, perioperative management details, and complications control. The goal of the present study was to 1) ascertain the indications for APC arthroplasty used in the proximal 
femur; 2) identify the perioperative management in our hospital; and 3) illustrate our experiences to avoid the complications of APC.

\section{Materials and methods}

We retrospectively reviewed the records of 28 patients with bone tumor of the proximal femur who underwent reconstruction with cemented APCs from 1997 to 2008 (Table 1). All operations were performed in West China Hospital, Sichuan University by a senior surgeon (CQT). Institutional Review Board approval was not deemed necessary for the following retrospective review. All principles outlined in the Declaration of Helsinki were followed. There were 13 male patients and 15 female patients, with age ranging from 17 to 58 years (average 35.2 years). The diagnosis was osteosarcoma in four patients, fibrosarcoma in two patients, Ewing's sarcoma in two patients, chondrosarcoma in five patients, malignant fibrous histiocytoma in three patients, metastasis from breast cancer in two patients, enchondroma in one patient, giant cell tumor of bone in four patients, aneurysmal bone cyst in two patients, and giant cell tumor of bone accompanied with aneurysmal bone cyst in three patients. Two patients (one with giant cell tumor of bone and one with giant cell tumor of bone accompanied with aneurysmal bone cyst) presented with pathologic fractures; one patient with malignant fibrous histiocytoma had a prior operation with osteoarticular allograft reconstruction fixed with a dynamic hip screw; the others had no treatment before admission.

\section{Preoperative assessment}

All patients were required to undergo 100\% magnified X-ray (Figure 1), a computed tomography scan, magnetic resonance imaging, and emission computed tomography. On the basis of these imaging results, we measured the exact boundary of the tumor, the resection length, the diameter and cortex thickness of the narrowest part of the medullary cavity, and the distance between the site of the osteotomy and the narrowest part of the medullary cavity. Next, the matched

Table I Details of the surgical technique and results in the 28 patients

\begin{tabular}{|c|c|c|c|c|c|c|c|}
\hline $\begin{array}{l}\text { Patient } \\
\text { number }\end{array}$ & $\begin{array}{l}\text { Age (years)/ } \\
\text { sex }\end{array}$ & Diagnosis & Stage & $\begin{array}{l}\text { Postoperative } \\
\text { chemotherapy }\end{array}$ & $\begin{array}{l}\text { Resection } \\
\text { length }(\mathrm{cm})\end{array}$ & $\begin{array}{l}\text { Type of } \\
\text { prosthesis }\end{array}$ & $\begin{array}{l}\text { Type of acetabular } \\
\text { reconstruction }\end{array}$ \\
\hline I & $20 / F$ & GCT & 3 & $N$ & 71 & DePuy solution & DePuy metal socket \\
\hline 2 & $37 / M$ & $\mathrm{MFH}$ & $\mathrm{Ib}$ & $\mathrm{Y}$ & 173 & DePuy solution & DePuy metal socket \\
\hline 3 & $29 / M$ & GCT\&ABC & 3 & $N$ & 92 & DePuy solution & DePuy metal socket \\
\hline 4 & $35 / F$ & GCT & 3 & $N$ & 76 & DePuy solution & DePuy metal socket \\
\hline 5 & $56 / M$ & CS & Il b & $Y$ & 170 & DePuy solution & DePuy metal socket \\
\hline 6 & $48 / F$ & CS & II b & $Y$ & $|5|$ & DePuy solution & DePuy metal socket \\
\hline 7 & $I 7 / F$ & OS & $\mathrm{II}$ a & $\mathrm{Y}$ & 145 & DePuy solution & DePuy metal socket \\
\hline 8 & $5 I / M$ & BM & III & $Y$ & 186 & DePuy solution & DePuy metal socket \\
\hline 9 & $27 / F$ & GCT & 3 & $N$ & 68 & DePuy solution & DePuy metal socket \\
\hline 10 & $2 \mathrm{I} / \mathrm{M}$ & ES & II a & $\mathrm{Y}$ & 185 & DePuy solution & DePuy metal socket \\
\hline II & $37 / M$ & $A B C$ & 3 & $N$ & 96 & DePuy solution & DePuy metal socket \\
\hline 12 & $20 / M$ & os & II b & Y & 191 & DePuy solution & DePuy metal socket \\
\hline 13 & $I 7 / F$ & CS & II b & $\mathrm{Y}$ & 165 & DePuy solution & DePuy bipolar prosthesis \\
\hline 14 & $47 / M$ & FS & Il b & $\mathrm{Y}$ & 187 & DePuy solution & DePuy bipolar prosthesis \\
\hline 15 & $58 / \mathrm{F}$ & CS & II b & Y & 168 & DePuy solution & DePuy metal socket \\
\hline 16 & $35 / M$ & BM & II b & $\mathrm{Y}$ & 185 & DePuy solution & DePuy bipolar prosthesis \\
\hline 17 & $46 / M$ & $A B C$ & 3 & $N$ & 102 & DePuy solution & DePuy metal socket \\
\hline 18 & $33 / F$ & GCT\&ABC & 3 & $N$ & 75 & DePuy solution & DePuy bipolar prosthesis \\
\hline 19 & $40 / F$ & MFH & II b & $\mathrm{Y}$ & 189 & DePuy solution & DePuy bipolar prosthesis \\
\hline 20 & $19 / F$ & os & $\mathrm{II}$ a & Y & 164 & DePuy solution & DePuy metal socket \\
\hline 21 & $29 / F$ & ENC & 3 & $N$ & 75 & DePuy solution & DePuy bipolar prosthesis \\
\hline 22 & $37 / F$ & FS & Il b & $\mathrm{Y}$ & 155 & DePuy solution & DePuy bipolar prosthesis \\
\hline 23 & $2 \mathrm{I} / \mathrm{F}$ & ES & II b & Y & 165 & DePuy solution & DePuy bipolar prosthesis \\
\hline 24 & $36 / M$ & GCT & 3 & $N$ & 92 & DePuy solution & DePuy bipolar prosthesis \\
\hline 25 & $55 / F$ & OS & II b & $\mathrm{Y}$ & 168 & DePuy solution & DePuy metal socket \\
\hline 26 & $34 / M$ & CS & II b & Y & 179 & DePuy solution & DePuy bipolar prosthesis \\
\hline 27 & $36 / M$ & MFH & II b & Y & 167 & DePuy solution & DePuy metal socket \\
\hline 28 & $44 / F$ & GCT\&ABC & 3 & $\mathrm{~N}$ & 75 & DePuy solution & DePuy bipolar prosthesis \\
\hline
\end{tabular}

Abbreviations: ABC, aneurysmal bone cyst; BM, bone metastasis of mammary carcinoma; CS, chondrosarcomas; ENC, enchondroma; ES, Ewing's sarcoma; F, female; FS, fibrosarcoma; GCT, giant cell tumor of bone; GCT\&ABC, giant cell tumor of bone accompanied with aneurysmal bone cyst; M, male; MFH, malignant fibrous histiocytoma; OS, osteosarcoma. 


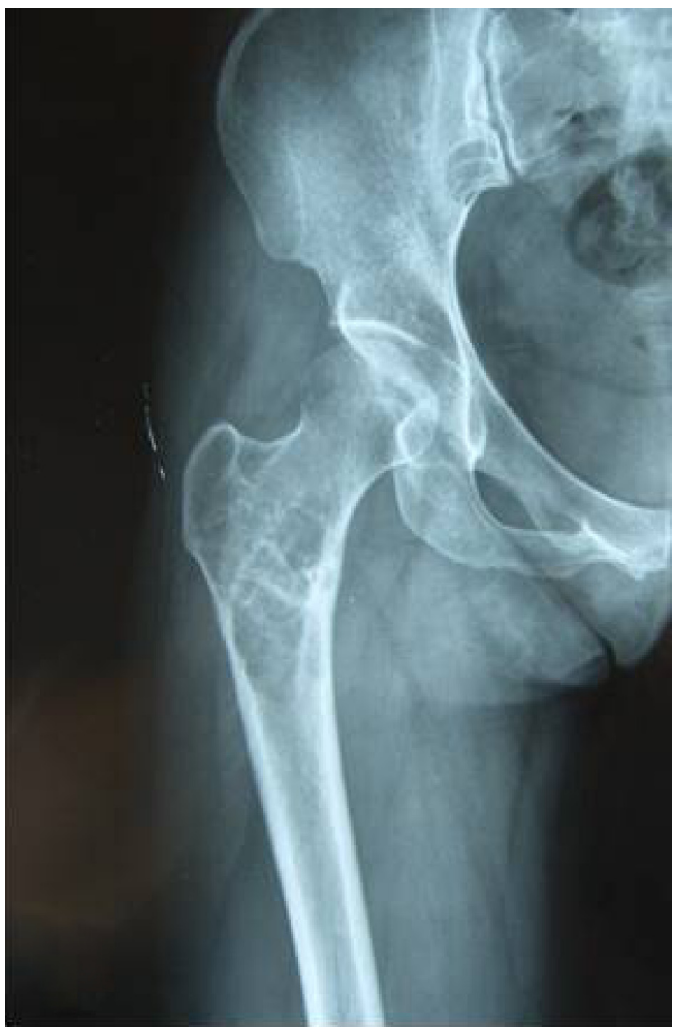

Figure I The radiograph shows the preoperative AP of a chondrosarcoma. Abbreviation: AP, anterior-posterior X-ray.

allograft was selected. Before surgery, a biopsy was done. Patients diagnosed as malignant bone tumor were treated with neoadjuvant chemotherapy routinely.

The allografts were harvested from cadaver donors, and the fresh-frozen allografts were cryopreserved in a freezer at $-80^{\circ} \mathrm{C}$ with the addition of dimethyl sulfoxide and rifampicin. All the grafts were obtained from the bone bank in Sichuan province, People's Republic of China.

\section{Perioperative management}

The patients were put in lateral position. A lateral approach was used in all cases, and the incision from the previous procedure was used, if possible, with excision of the previous scar. All previous biopsy sites, including any needle biopsy tracks, were removed en bloc. The surgical procedure included two major steps - resection and reconstruction.

If possible, the abductor muscles and iliopsoas was marked for reconstruction. Before osteotomy, the exact resection length was measured again. For aggressive benign tumors, an excision with a least a $2 \mathrm{~cm}$ safe margin was performed; for primary malignant tumors, an excision with a least a $5 \mathrm{~cm}$ safe margin was performed; for metastatic malignant tumors, an excision with a least a $2-5 \mathrm{~cm}$ safe margin was performed.
The distal femoral cut was horizontal. The resection length, measured from the tip of the greater trochanter, ranged from 6.8 to $19.1 \mathrm{~cm}$ (average $14.0 \mathrm{~cm}$ ) in all patients; it ranged from 6.8 to $10.2 \mathrm{~cm}$ (average $8.2 \mathrm{~cm}$ ) in the eleven benign tumor cases and ranged from 14.5 to $19.1 \mathrm{~cm}$ (average $17.2 \mathrm{~cm}$ ) in the 17 malignant tumor cases. Before osteotomy, a $1.0-1.5 \mathrm{~cm}$ normal periosteal cuff was left if possible. After osteotomy, the medullary tissue of the distal femur was sent for frozen biopsy in order to ensure the en bloc resection.

Reconstruction was performed during the same surgery. The allograft was prepared to correctly match the length of the bone defect. Next, the allograft and host femur were reamed to fit the prosthesis, and the greater and lesser trochanters were prepared for the soft tissue reconstruction by drilling holes in the graft. The allograft was degreased with medical alcohol and pulsatile lavaged with abundant normal saline. After a trial fitting, we cemented the prosthesis into the allograft (on a back table) and performed a second trial after the cement polymerization was complete. The composite prosthesis was cemented into the host bone, and care was taken no cement was caught between the allograft and the host bone. All the allograft-host bone junctions were filled with granular allogeneic spongy bone and covered by the periosteal cuff. Fifteen of the patients underwent total hip replacement, and the remaining seven patients underwent bipolar replacement (Figure 2).

Finally, the attachment of the important muscles was reconstructed. A total of 12 patients who had a greater trochanter remaining had the trochanter reattached directly to the allograft, with a $2.0 \mathrm{~mm}$ nonabsorbable suture; a total of 16 patients who had no trochanter remaining had the gluteus medius and gluteus minimus sutured to the greater trochanter of the allograft, with a $2.0 \mathrm{~mm}$ nonabsorbable suture. All patients had the gluteus medius, the vastus lateralis, and the fascia lata sutured together. The iliopsoas was sutured to the lesser trochanter of the allograft. However, the gluteus maximus tendon was not reattached to its anatomic place.

\section{Postoperative management}

After surgery, we routinely used prophylactic intravenous (IV) antibiotics for 1-2 days. The rehabilitation program was designed on the basis of the surgeon's assessment during operation. Generally, the lower extremity was fixed in the abduction-neutral position by a brace, and the quadriceps femoris was exercised in bed for 4 weeks after surgery. During the process, deep vein thrombosis (DVT) prophylaxis was used until the patient was partial weight bearing. Partial and full weight bearing were permitted 4 and 12 weeks after surgery, respectively. 


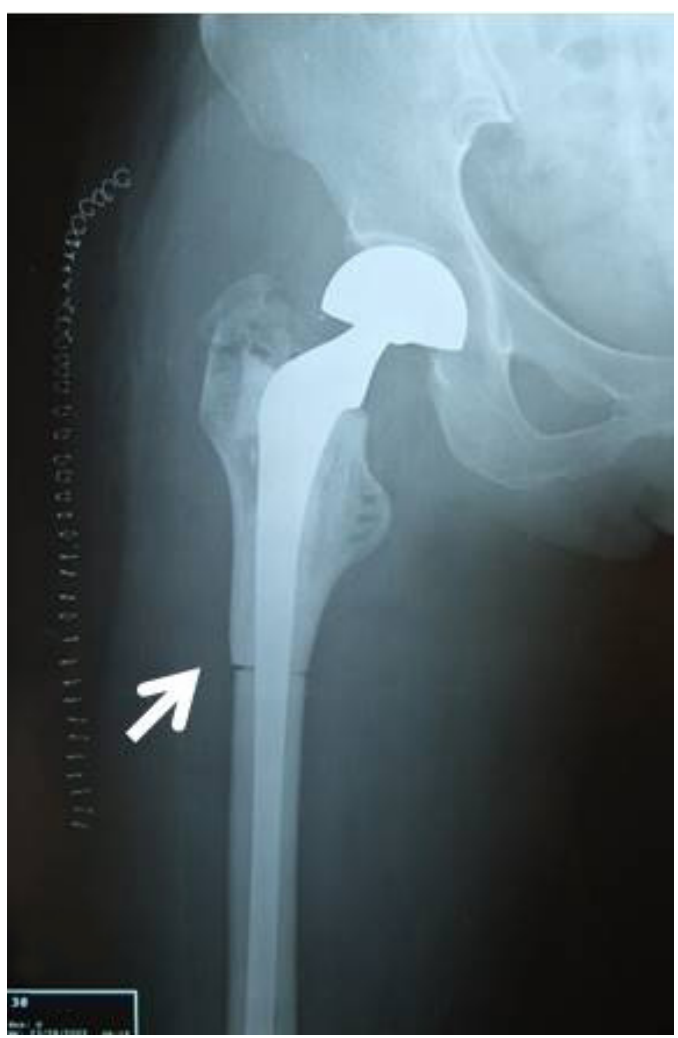

Figure 2 The radiograph shows the immediate postoperative AP of a cemented allograft prosthesis composite for a chondrosarcoma (Ennecking IA).

Note: The white arrow indicates the allograft host-bone junction. Abbreviation: AP, anterior-posterior X-ray.

\section{Follow-up}

All patients were followed up clinically every 1 month during the first half-year, every 3 months during the first 2 years, and then once or more in 1 year. Three patients were deceased at the follow-up points of 15,17 , and 21 months because of lung metastasis of osteosarcoma and chondrosarcoma, and skeletal metastasis of breast cancer. We performed radiographic assessment at 1 month, 3 months, 6 months, 9 months, and 12 months after surgery and then, annually, but we had only 16 (57.1\%) patients with radiographic follow-up more than 2 years. The Musculoskeletal Tumor Society (MSTS) scoring system and Harris Hip Score (HHS) (for which a score of $<70$ is poor, $70-79$ is fair, $80-89$ is good, and $90-100$ is excellent) were used to assess functional outcome. ${ }^{6,7}$ All the deceased patients were excluded from our results. Excluding the three deceased patients, the general follow-up ranged from 25 to 138 months, with a median follow-up of 56 months (Table 2).

\section{Statistical analysis}

The Wilcoxon signed-rank test was employed for comparison of two related nonparametric data. The Mann-Whitney test was employed for comparison of two independent nonparametric data. A $P$-value of 0.05 or less was considered statistically significant.

\section{Results}

\section{Radiographic analysis}

Routine anteroposterior and lateral radiographs were assessed for evidence of union at the junction of allograft and host bone, trochanteric union, resorption, and periprosthetic fracture.

We defined the union at the allograft and host bone junction by radiographic evidence of blurring, with bridging trabeculae at the junction and no radiolucent lines around the junction. ${ }^{8}$ Nonunion was not diagnosed until at least 1 year without further progress toward union had passed. ${ }^{9}$ In our series, except for the three cases of death, union occurred in 22 (88.0\%) patients (range 9-18 months) in which there were nine (36.0\%) patients (range 13-18 months) with delayed union.

Trochanteric union was defined as a lack of migration of the greater trochanter, with trabecular bridging; migration or a gap of more than $1 \mathrm{~cm}$ was regarded as nonunion. ${ }^{10}$ Nonunion of the greater trochanter was seen in six of the 12 patients (50.0\%) in whom the host trochanter was preserved (Figure 3).

There were eight hips $(32.0 \%)$ in which there was resorption (Figure 3), categorized as mild, moderate, or severe according to the thickness of bony involvement: five $(20.0 \%)$ with mild (partial) resorption of the allograft, two (8.0\%) with moderate (about 50\% loss of thickness) resorption, and one (4.0\%) with severe (almost full thickness) resorption. ${ }^{11}$ Resorption was most common in Gruen zone VII (three hips), zone I (two hips), and zone II (one hip), and two hips had resorption in both zone I and VII. Among these patients, no symptoms were observed at their last follow-up point, therefore another round of revision surgery was not required, except for one patient with periprosthetic fracture and progressive wear of the acetabulum.

There were two hips $(8.0 \%)$ that were observed to have asymptomatic wear of the acetabulum at the follow-up points of 6 years and 8 years. One patient who had a prior revision with extended stem APC revision was severely symptomatic at the follow-up point of 10 years because of progressive wear of the acetabulum and the periprosthetic fracture (Gruen zone III, Vancouver B1), which meant that an additional revision surgery was required (Figures 4, 5). We did revision using extended stem prosthesis and graft implantation (Figure 6). This hip showed good stability at the last follow-up examination.

\section{Clinical evaluation}

Functional results were evaluated in 25 patients having a follow-up of at least 2 years. The Musculoskeletal Tumor 
Table 2 The follow-up results of 28 patients

\begin{tabular}{|c|c|c|c|c|c|}
\hline $\begin{array}{l}\text { Patient } \\
\text { number }\end{array}$ & $\begin{array}{l}\text { Follow-up } \\
\text { (months) }\end{array}$ & Status & $\begin{array}{l}\text { MSTS } \\
\text { score }\end{array}$ & Complications & $\begin{array}{l}\text { Operation for } \\
\text { complication }\end{array}$ \\
\hline I & 62 & NED & 24 & Trochanteric nonunion; resorption & None \\
\hline 2 & 138 & NED & 26 & $\begin{array}{l}\text { Delayed union; progressive wear of } \\
\text { acetabulum; periprosthetic fracture; resorption }\end{array}$ & $\begin{array}{l}\text { Prosthetic substitution } \\
\text { and bone graft }\end{array}$ \\
\hline 3 & 94 & NED & 28 & Delayed union; resorption & None \\
\hline 4 & 49 & NED & 28 & Delayed union; trochanteric nonunion & None \\
\hline 5 & 101 & NED & 23 & Nonunion; progressive wear of acetabulum & None \\
\hline 6 & 15 & DOD & NE & NE & None \\
\hline 7 & 42 & NED & 28 & Resorption & None \\
\hline 8 & 17 & DOD & NE & NE & None \\
\hline 9 & 85 & NED & 26 & Trochanteric nonunion & None \\
\hline 10 & 73 & NED & 28 & Delayed union & None \\
\hline II & 74 & NED & 26 & Trochanteric nonunion; resorption & None \\
\hline 12 & 20 & DOD & NE & NE & None \\
\hline 13 & 53 & NED & 21 & Nonunion & None \\
\hline 14 & 46 & NED & 25 & Delayed union & None \\
\hline 15 & 48 & NED & 26 & Resorption & None \\
\hline 16 & 51 & NED & 29 & None & None \\
\hline 17 & 38 & NED & 29 & None & None \\
\hline 18 & 41 & NED & 26 & Delayed union; trochanteric nonunion & None \\
\hline 19 & 44 & NED & 28 & None & None \\
\hline 20 & 38 & NED & 28 & None & None \\
\hline 21 & 48 & NED & 26 & Resorption & None \\
\hline 22 & 41 & NED & 29 & None & None \\
\hline 23 & 38 & NED & 24 & Nonunion & None \\
\hline 24 & 41 & NED & 25 & Delayed union & None \\
\hline 25 & 37 & NED & 26 & Delayed union; resorption & None \\
\hline 26 & 27 & NED & 29 & None & None \\
\hline 27 & 33 & NED & 29 & None & None \\
\hline 28 & 25 & NED & 26 & Delayed union; trochanteric nonunion & None \\
\hline
\end{tabular}

Abbreviations: DOD, died of disease; MSTS, Musculoskeletal Tumor Society; NE, no evidence; NED, no evidence of disease.

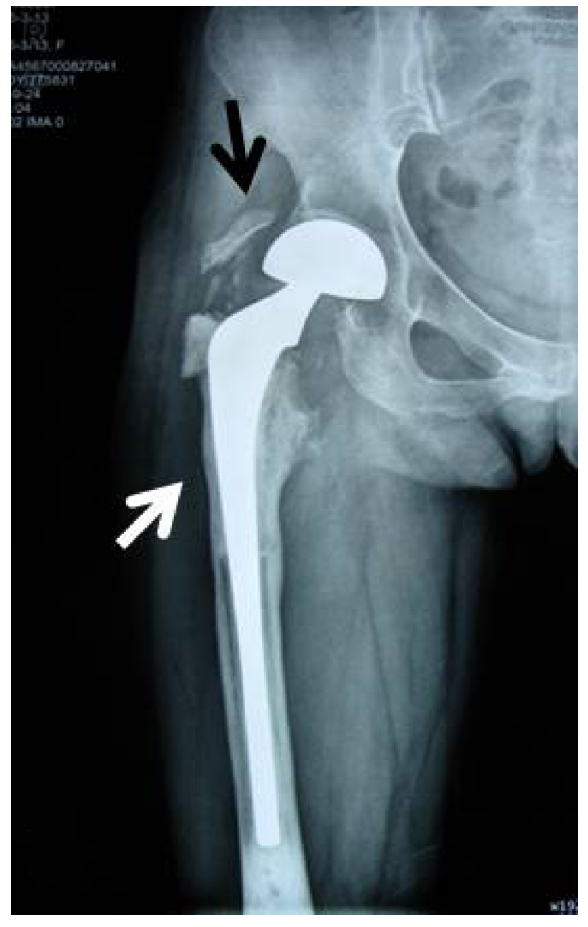

Figure 3 The radiograph shows an 8-year postoperative AP of a cemented allograft prosthesis composite for a chondrosarcoma (IA).

Notes: The white arrow indicates the resorption site; the black arrow indicates the nonunion of trochanter.

Abbreviation: AP, anterior-posterior X-ray.
Society (MSTS) scoring system was used for evaluation. The average functional score was 26.5 points (range 21-29 points). Wilcoxon signed-rank test showed a significant difference between the preoperative MSTS score and the postoperative score $(P=0.000)$. Mann-Whitney test showed that there was no significant difference in MSTS score at the last follow-up between patients with benign tumor and those with a malignant lesion $(P=0.567)$, and there was no significant difference in the MSTS score at the last follow-up between patients with total hip and those with bipolar prosthesis $(P=0.609)$.

We compared preoperative HHS score with the score at the last follow-up examination. The average preoperative score was 48.0 points (range $40.3-58.5$ points), and the average postoperative score was 80.6 points (range $66.2-92.7$ points). Wilcoxon signed-rank test showed that there was a significant difference between the preoperative HHS score and the postoperative score $(P=0.000)$. Mann-Whitney test showed that there was a significant difference in HHS score at the last follow-up between patients with benign and those with malignant tumor $(P=0.909)$, and there was no significant difference in HHS score at the last follow-up between patients with total hip and those with bipolar prosthesis $(P=0.979)$. 


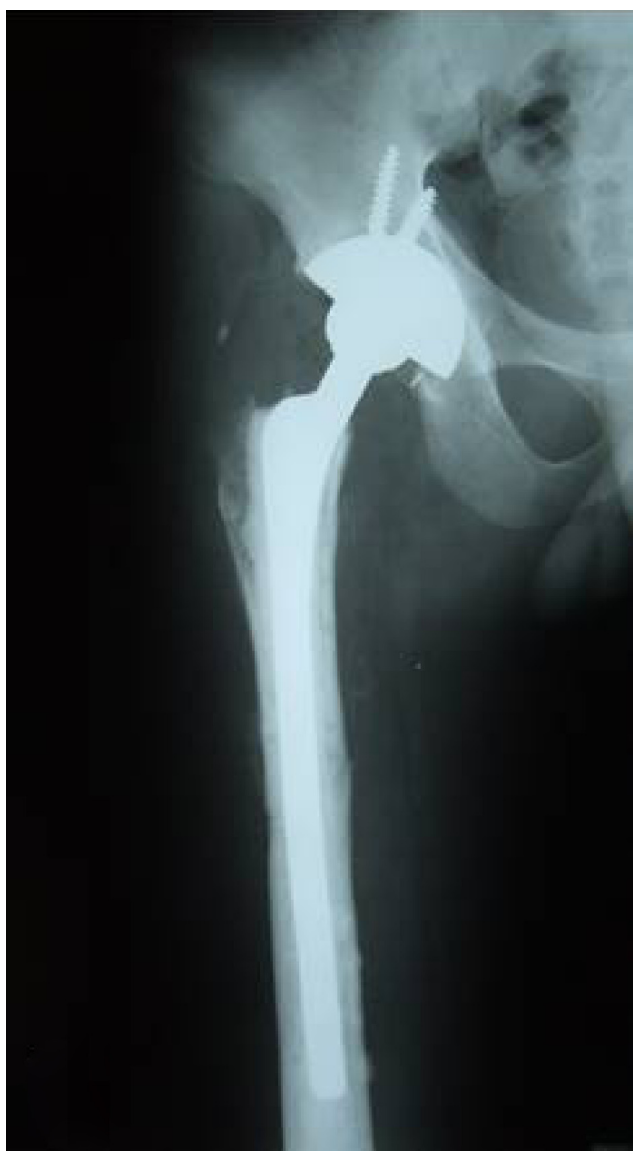

Figure 4 The radiograph shows a 6-year postoperative AP of a cemented allograft prosthesis composite for a malignant fibrous histiocytoma before revision. Abbreviation: AP, anterior-posterior X-ray.

There were no cases of recurrence, but metastasis was found in two hips (less than 20 months), which caused the death finally, and the diagnosis in these two cases were osteosarcoma and chondrosarcoma. All of the three deceased patients had undergone sufficient neoadjuvant chemotherapy.

\section{Complications}

We divided complications into intraoperative and postoperative categories. During surgery, there was no neurovascular injury, fracture, fat embolism, coagulopathy, or pulmonary edema. In the late phase, however, there were many complications, including nonunion, nonunion of the greater trochanter, resorption, progressive wear of the acetabulum, and periprosthetic fracture. Nonunion was one of the most serious and worrisome complications: three hips $(12.0 \%)$ had nonunion of the bone-allograft junction (Figure 7), nine hips $(36.0 \%)$ had delayed union, and six hips (50.0\%) had nonunion in the greater trochanter. As mentioned earlier, eight hips (32.0\%) had resorption of the allograft, and two hips $(8.0 \%)$ had progressive wear of the acetabulum in which one hip had periprosthetic fracture - only one of the hips with

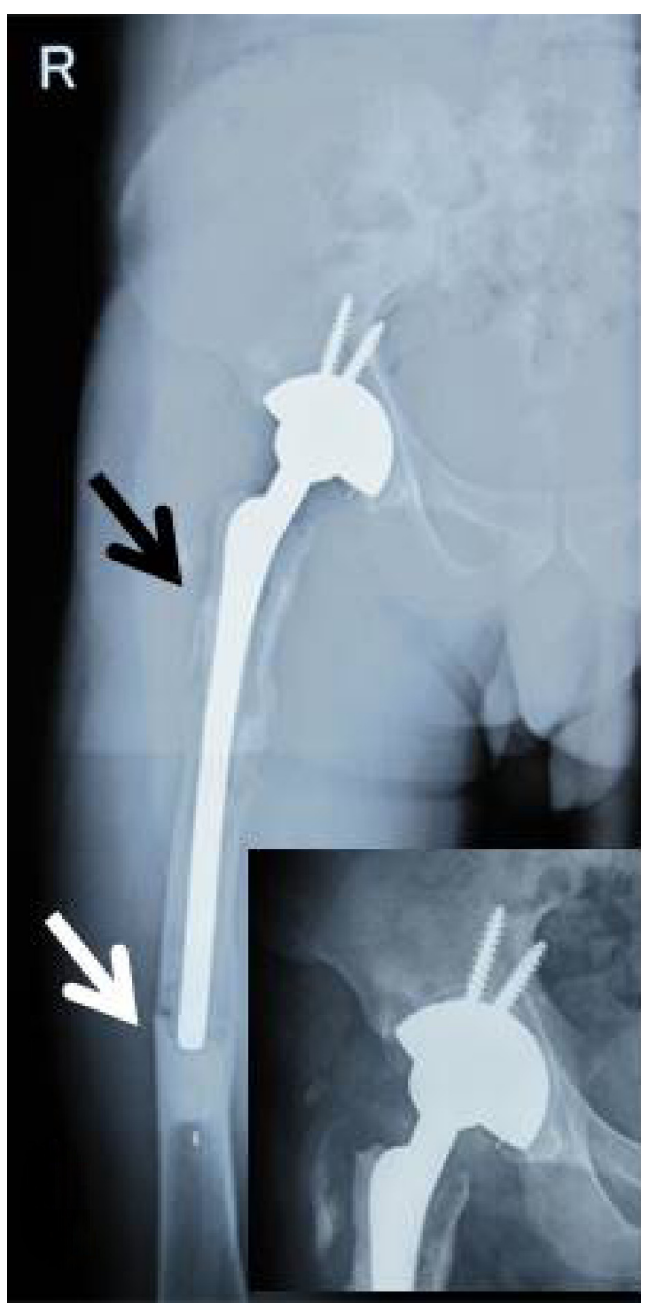

Figure 5 The radiograph shows a 10-year postoperative AP of a cemented allograft prosthesis composite for a malignant fibrous histiocytoma before revision. Notes: The radiograph shows the severe wear of the acetabulum. The white arrow indicates the periprosthetic fracture; the black arrow indicates the resorption. Abbreviation: AP, anterior-posterior X-ray.

periprosthetic fracture and progressive wear of the acetabulum underwent additional revision surgery, at 10 years after the original revision (Figures 5-7). Up to now, in our series, there has been no infection, dislocation, or chronic allergic reaction cases.

\section{Discussion}

APCs have generated substantial interest since the late 1980s, but the indications for APC arthroplasty, how to improve the perioperative management, and the methods to avoid the complications associated with APC are still the key points of the clinical application.

We acknowledge some limitations of this study. This was a retrospective study performed on a group of patients receiving proximal femoral reconstruction after bone tumor resection. We had too few patients to stratify patients by age, postoperative chemotherapy, length of resection, or pathology. Thus, 


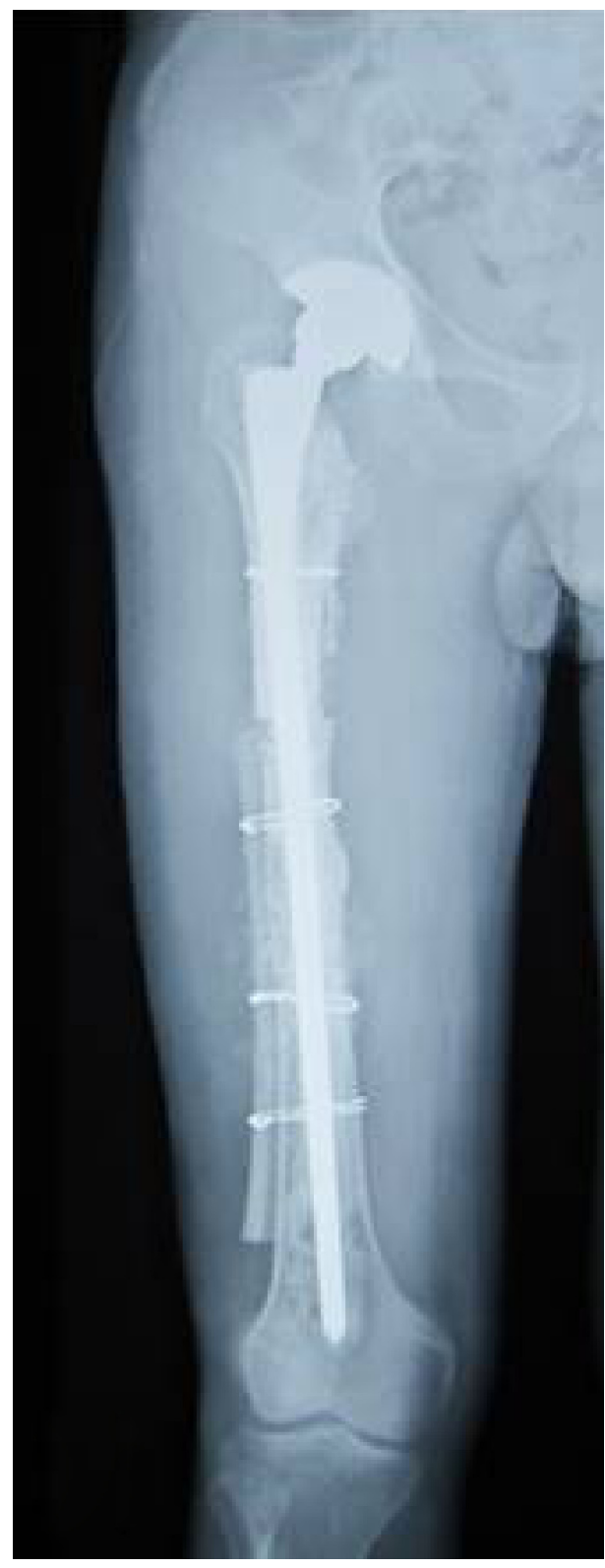

Figure 6 The radiograph shows a I-year postoperative AP after uncemented allograft prosthesis composite revision.

Abbreviation: AP, anterior-posterior X-ray.

some of our questions could not be definitely addressed by the study. Given the relative rarity of this problem and the unique treatment for each individual, it would be difficult to obtain a large series with sufficient power to address these important questions. Nevertheless, we could see some meaningful trends.

The selection of patients who are appropriate for limbsparing surgery of the proximal femur is vitally important and is more likely to affect the clinical and functional results than is the choice of implant. But until now, the indications have not been absolutely established. Gross and Hutchison support the use of proximal femoral allograft for the reconstruction of circumferential defects of more than $3 \mathrm{~cm}$ in length from

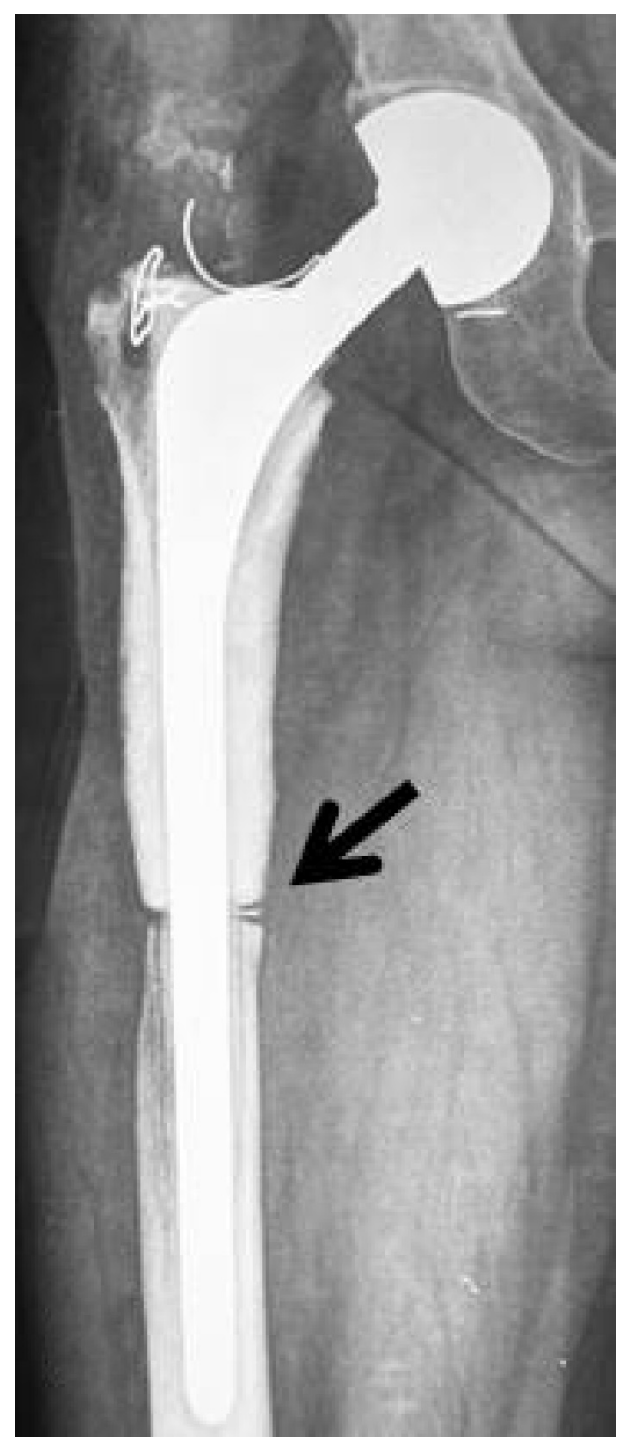

Figure 7 The radiograph shows a 3-year postoperative AP of a cemented allograft prosthesis composite for an osteosarcoma.

Note: The black arrow indicates the allograft host-bone nonunion because of the cement in the junction.

Abbreviation: AP, anterior-posterior X-ray.

the calcar, some combined defects, and in some cases of femoral discontinuity. ${ }^{12}$ Donati et al thought the APC should be used in younger patients with a longer life expectancy, when substantial portions of the periacetabular muscles and tendons can be spared and there is no plan to use radiation therapy that can interfere with bone healing. ${ }^{13}$ In our opinion, besides the indication of limb salvage surgery, the indications for cemented APC arthroplasty for the proximal femur are: 1) tumor involving the proximal femur and with inferior edge surpassing the lesser trochanter; 2) (for metastatic tumors) a single metastatic site discovered at least 2 years after diagnosis of the original cancer; 3) long expected nondisease survival time; 4) revision of an osteoarticular allograft replacement and additional revision of original APC 
arthroplasty; and 5) complications of allograft are acceptable to the patient and family.

It is always more important to ensure the en bloc resection of the tumor than reconstruction. Although preoperative radiographic assessments were used to delineate the extent of the tumor and we strictly conformed to principles for resection of bone tumors, there was still the possibility that en bloc resection could not be achieved. Therefore, after the osteotomy, all the patients underwent the frozen biopsy of the medullary tissues of the distal femur.

Because nonunion or delayed union is one of the main disadvantages of large structural allografts, reportedly $3.5 \%-23 \%$ and $56 \%$, respectively, ${ }^{14-18}$ avoiding this common problem is desirable. In our series, there were three hips (12.0\%) with nonunion of the bone-allograft junction, and nine hips (36.0\%) with delayed union. Although the factors affecting bone union are bone grafting at the junction, postoperative chemotherapy, and radiotherapy, ${ }^{19,20}$ we paid more attention to the management of the junction of the allograft-host bone. In order to enhance union, some authors advise performing step-cut osteotomy and telescope apposition (intussusception of the allograft bone into the host) to increase the bone contact. ${ }^{21,22}$ In our series, because of the technique difficulty and the risk of inadequate contact, horizontal osteotomy was chosen, periosteum around the osteotomy was preserved, and additional bone grafting was used.

Nowadays cementing the prosthesis proximally into the graft is widely accepted. ${ }^{1,21,23}$ However, the methods for distal fixation of the composite to the host bone are varied, including distal cementing, interlocking fixation, ${ }^{24}$ or press fit without cement. The distal cementing method allowed immediate weight bearing and revealed good initial stability. But it has its own disadvantages: 1) the risk of nonunion caused by the cement between the allograft and the host bone; 2) the greater difficulty and destructiveness to the remaining host bone, if revision is needed; 3 ) the risk of cement-related adverse effects, such as cardiovascular toxicity; and 4) poorer potential for union of the junction than cementless fixation, as reported by some studies. ${ }^{25}$

The rate of graft resorption using cemented fixation have been reported as ranging from $28.6 \%$ to $47.6 \%,{ }^{21,26}$ and the studies using fresh-frozen allograft have always had a better result for resorption because radiation affects the structural properties of allografts and increases the risk for fracture of massive allografts. ${ }^{27-29}$ Previous 10-year and longer follow-up studies of normal total hip arthroplasty have shown that the resorption of the proximal femur was always observed in the Gruen zone I and VII. ${ }^{30,31}$ Lee et al reported seven hips $(46.6 \%)$ in which there was resorption, and resorption was most common in Gruen zone VII (five hips) and zone II (one hip), with one hip having resorption in both zones. ${ }^{25} \mathrm{In}$ our study, we had seven (31.8\%) resorption cases, and the incidence and the distribution of the sites of resorption was nearly the same as in previous studies.

Other studies have reported that infection rates ranged from $0.3 \%$ to $20 \%$, and the researchers involved performed oneor two-stage repeat revision surgery to control infection. ${ }^{21,32}$ Numerous risk factors have been implicated in the development of postoperative infection, such as comorbidities, ${ }^{33-35}$ previous surgery, ${ }^{36}$ complexity and duration of the operation, ${ }^{35,36}$ prophylactic antibiotic protocol, ${ }^{36-38}$ blood transfusion, ${ }^{33,34,38}$ radiation, and chemotherapy. ${ }^{37-39}$ In our study, there were no cases of infection, for three reasons: Firstly, an experienced oncologic surgeon can reduce the duration of surgery and thus, decrease the exposure of the wound. Secondly, the management of the fresh-frozen allograft is much more important we, not only sterilized it through immersion in iodophors for at least 30 minutes but also, lessened its antigenicity through repeated degreasing with medical alcohol and pressure irrigation with abundant amounts of normal saline. Thirdly, during the perioperative period, we paid attention to the systemic condition of the patients, the usage of antibiotics, and to proper prolongation of the postoperative drainage.

\section{Conclusion}

Cemented APC reconstruction provides a means for reconstruction of the proximal femur. But only if the exact indications for cemented APC arthroplasty are understood, correct perioperative procedure is complied with, and complications are controlled, can cemented APC reconstruction be proposed as the better alternative.

\section{Disclosure}

The authors report no conflicts of interest in this work.

\section{References}

1. Farid Y, Lin PP, Lewis VO, Yasko AW. Endoprosthetic and allograftprosthetic composite reconstruction of the proximal femur for bone neoplasms. Clin Orthop Relat Res. 2006;442:223-229.

2. Finstein JL, King JJ, Fox EJ, Ogilvie CM, Lackman RD. Bipolar proximal femoral replacement prostheses for musculoskeletal neoplasms. Clin Orthop Relat Res. 2007;459:66-75.

3. Menendez LR, Ahlmann ER, Kermani C, Gotha H. Endoprosthetic reconstruction for neoplasms of the proximal femur. Clin Orthop Relat Res. 2006;450:46-51.

4. Selek H, Başarir K, Yildiz Y, Sağlik Y. Cemented endoprosthetic replacement for metastatic bone disease in the proximal femur. J Arthroplasty. 2008;23(1):112-117. 
5. Park YS, Moon YW, Lee BT, Wang JH. Structural allograft for femoral deficiency in revision total hip arthroplasty. J Korean Orthop Assoc. 2004:39:7.

6. Enneking WF, Dunham W, Gebhardt MC, Malawar M, Pritchard DJ. A system for the functional evaluation of reconstructive procedures after surgical treatment of tumors of the musculoskeletal system. Clin Orthop Relat Res. 1993;(286):241-246.

7. Harris WH. Traumatic arthritis of the hip after dislocation and acetabular fractures: treatment by mold arthroplasty. An end-result study using a new method of result evaluation. J Bone Joint Surg Am. 1969;51(4):737-755.

8. Head WC, Wagner RA, Emerson RH Jr, Malinin TI. Revision total hip arthroplasty in the deficient femur with a proximal load-bearing prosthesis. Clin Orthop Relat Res. 1994;(298):119-126.

9. Gross AE, Hutchison CR, Alexeeff M, Mahomed N, Leitch K, Morsi E. Proximal femoral allografts for reconstruction of bone stock in revision arthroplasty of the hip. Clin Orthop Relat Res. 1995;151-158.

10. Graham NM, Stockley I. The use of structural proximal femoral allografts in complex revision hip arthroplasty. J Bone Joint Surg Br. 2004;86(3):337-343.

11. Haddad FS, Garbuz DS, Masri BA, Duncan CP. Structural proximal femoral allografts for failed total hip replacements: a minimum review of five years. J Bone Joint Surg Br. 2000;82(6):830-836.

12. Gross AE, Hutchison CR. Proximal femoral allografts for reconstruction of bone stock in revision hip arthroplasty. Orthopedics. 1998;21(9):999-1001.

13. Donati D, Giacomini S, Gozzi E, Mercuri M. Proximal femur reconstruction by an allograft prosthesis composite. Clin Orthop Relat Res. 2002;(394):192-200.

14. Donati D, Colangeli M, Colangeli S, Di Bella C, Mercuri M. Allograftprosthetic composite in the proximal tibia after bone tumor resection. Clin Orthop Relat Res. 2008;466(2):459-465.

15. Biau DJ, Davis A, Vastel L, Tomeno B, Anract P. Function, disability, and health-related quality of life after allograft-prosthesis composite reconstructions of the proximal femur. J Surg Oncol. 2008;97(3):210-215.

16. Maclachlan CE, Ries MD. Intramedullary step-cut osteotomy for revision total hip arthroplasty with allograft-host bone size mismatch. $J$ Arthroplasty. 2007;22(5):657-662.

17. Steinberg EL, Luger E, Zwas T, Katznelson A. Very long-term radiographic and bone scan results of frozen autograft and allograft bone grafting in 17 patients (20 grafts) a 30- to 35-year follow-up. Cell Tissue Bank. 2004;5(2):97-104.

18. Mankin HJ, Gebhardt MC, Jennings LC, Springfield DS, Tomford WW. Long-term results of allograft replacement in the management of bone tumors. Clin Orthop Relat Res. 1996;324:86-97.

19. Hanson PD, Warner C, Kofroth R, et al. Effect of intramedullary polymethylmethacrylate and autogenous cancellous bone on healing of frozen segmental allografts. J Orthop Res. 1998;16(3):285-292.

20. Hornicek FJ, Gebhardt MC, Tomford WW, et al. Factors affecting nonunion of the allograft-host junction. Clin Orthop Relat Res. 2001;382:87-98.

21. Langlais F, Lambotte JC, Collin P, Thomazeau H. Long-term results of allograft composite total hip prostheses for tumors. Clin Orthop Relat Res. 2003;414:197-211.

22. Healey JH, Abdeen A, Morris CD, Athanasian EA, Boland PJ. Telescope allograft method to reconstitute the diaphysis in limb salvage surgery. Clin Orthop Relat Res. 2009;467(7):1813-1819.
23. Haddad FS, Spangehl MJ, Masri BA, Garbuz DS, Duncan CP. Circumferential allograft replacement of the proximal femur. A critical analysis. Clin Orthop Relat Res. 2000;371:98-107.

24. Head WC, Berklacich FM, Malinin TI, Emerson RH Jr. Proximal femoral allografts in revision total hip arthroplasty. Clin Orthop Relat Res. 1987;225:22-36.

25. Lee SH, Ahn YJ, Chung SJ, Kim BK, Hwang JH. The use of allograft prosthesis composite for extensive proximal femoral bone deficiencies: a 2- to 9.8-year follow-up study. J Arthroplasty. 2009;24(8):1241-1248.

26. Anract P, Coste J, Vastel L, Jeanrot C, Mascard E, Tomeno B. [Proximal femoral reconstruction with megaprosthesis versus allograft prosthesis composite. A comparative study of functional results, complications and longevity in 41 cases]. Rev Chir Orthop Reparatrice Appar Mot. 2000;86(3):278-288. French.

27. Akkus O, Belaney RM, Das P. Free radical scavenging alleviates the biomechanical impairment of gamma radiation sterilized bone tissue. J Orthop Res. 2005;23(4):838-845.

28. Mitchell EJ, Stawarz AM, Kayacan R, Rimnac CM. The effect of gamma radiation sterilization on the fatigue crack propagation resistance of human cortical bone. J Bone Joint Surg Am. 2004;86-A(12):2648-2657.

29. Lietman SA, Tomford WW, Gebhardt MC, Springfield DS, Mankin HJ. Complications of irradiated allografts in orthopaedic tumor surgery. Clin Orthop Relat Res. 2000;375:214-217.

30. Breusch SJ, Lukoschek M, Thomsen M, MauH, EwerbeckV, Aldinger PR. Ten-year results of uncemented hip stems for failed intertrochanteric osteotomy. Arch Orthop Trauma Surg. 2005;125(5):304-309.

31. Götze C, Tschugunow A, Götze HG, Böttner F, Pötzl W, Gosheger G. Long-term results of the metal-cancellous cementless Lüberk total hip arthroplasty: a critical review at 12.8 years. Arch Orthop Trauma Surg. 2006;126(1):28-35.

32. Kwong FN, Ibrahim T, Power RA. Incidence of infection with the use of non-irradiated morcellised allograft bone washed at the time of revision arthroplasty of the hip. J Bone Joint Surg Br. 2005;87(11): 1524-1526.

33. Liu SA, Wong YK, Poon CK, Wang CC, Wang CP, Tung KC. Risk factors for wound infection after surgery in primary oral cavity cancer patients. Laryngoscope. 2007;117(1):166-171.

34. Morris CD, Sepkowitz K, Fonshell C, et al. Prospective identification of risk factors for wound infection after lower extremity oncologic surgery. Ann Surg Oncol. 2003;10(7):778-782.

35. Neumayer L, Hosokawa P, Itani K, El-Tamer M, Henderson WG, Khuri SF. Multivariable predictors of postoperative surgical site infection after general and vascular surgery: results from the patient safety in surgery study. J Am Coll Surg. 2007;204(6):1178-1187.

36. Penel N, Nicolas P, Yazdanpanah Y, et al. Prevention of surgical site infection after breast cancer surgery by targeted prophylaxis antibiotic in patients at high risk of surgical site infection. $J$ Surg Oncol. 2007;96(2):124-129.

37. Konishi T, Watanabe T, Kishimoto J, Nagawa H. Elective colon and rectal surgery differ in risk factors for wound infection: results of prospective surveillance. Ann Surg. 2006;244(5):758-763.

38. Olsen MA, Lefta M, Dietz JR, et al. Risk factors for surgical site infection after major breast operation. J Am Coll Surg. 2008;207(3):326-335.

39. Jeys LM, Grimer RJ, Carter SR, Tillman RM. Periprosthetic infection in patients treated for an orthopaedic oncological condition. $J$ Bone Joint Surg Am. 2005;87(4):842-849.
OncoTargets and Therapy

\section{Publish your work in this journal}

OncoTargets and Therapy is an international, peer-reviewed, open access journal focusing on the pathological basis of all cancers, potential targets for therapy and treatment protocols employed to improve the management of cancer patients. The journal also focuses on the impact of management programs and new therapeutic agents and protocols on

\section{Dovepress}

patient perspectives such as quality of life, adherence and satisfaction. The manuscript management system is completely online and includes a very quick and fair peer-review system, which is all easy to use. Visit http://www.dovepress.com/testimonials.php to read real quotes from published authors. 